\title{
El Régimen de Copropiedad y sus Problemas Jurídicos
}

The Copyright Regime and its Legal Problems

\author{
María Gabriela Morillo Chamorro \\ Investigadora Jurídica, PUCE Quito
}

Mgtr. Gonzalo Lascano Báez

Decente titular PUCE (Facultad de Jurisprudencia)

Artículo Original (Revisión)

RFJ, No. 3, 2018, pp. 143-158, ISSN 2588-0837

RESUMEN: la copropiedad o condominio ocurre cuando el dominio de un objeto corresponde a una pluralidad de sujetos; es así que hay un cuasicontrato de comunidad cuando aquel dominio que recae sobre una cosa o de un derecho pertenece pro indiviso a varias personas que se vuelven copropietarios o comuneros entre sí. Este régimen imperfecto es susceptible de ocasionar problemas derivados del ejercicio conjunto de las facultades del dominio, que desembocan en la necesidad de la tutela judicial para resolver los conflictos que se producen entre copropietarios o comuneros.

PALABRAS CLAVE: copropiedad, condominio, bien, derecho, propiedad.

ABSTRACT: the situation of co-ownership or condominium is given when the property of an object corresponds to a plurality of subjects. There is a quasi-contract of community when the property of a thing or a right belongs undivided to several people and become commoners. It is because of this emerging situation that the problems arise when one of the co-owners no longer wants to continue to be a shareholder of a good and it is up to the judge to make the division of the common thing without any of the parties feeling affected or harmed.

KEY WORDS: co-ownership, condominium, good, right, property. 


\section{INTRODUCCIÓN}

La copropiedad también conocida como condominio o comunidad, se refiere a la modalidad del dominio en la cual existe un solo dominio, pero este se encuentra dividido en cuotas entre varios titulares. El efecto práctico es que dos o más personas comparten la propiedad de una cosa. La copropiedad puede provenir de la voluntad de los copropietarios, como por ejemplo las cosas que se aportan a una sociedad o que son adquiridas en común. También puede originarse en la ley, cuyos ejemplos más evidentes son la sociedad conyugal y la herencia; $y$, finalmente, puede originarse de manera forzosa a través de una orden judicial (v.g en la adjudicación de derechos y acciones de un bien a un tercero).

En el presente ensayo de reflexión se revisará el concepto y naturaleza jurídica de la copropiedad, vislumbrando sus características principales a la luz de las distintas teorías jurídicas que abordan su tratamiento jurídico. A continuación se determinarán las clases de copropiedad, los derechos de los copropietarios entre sí, y la importancia de la administración del bien común; luego, se analizará la propiedad horizontal distinguiendo esta última de la copropiedad. Finalmente, se abordará las soluciones jurídicas al problema de la división de la cosa o bien común, los problemas derivados de esta modalidad del dominio en el Ecuador.

\section{CONCEPTO Y NATURALEZA JURÍDICA DE LA COPRO- PIEDAD}

La doctrina tradicional, de inspiración romana, considera la copropiedad como una forma de propiedad individual. Cada copropietario es dueño de una cuota, parte ideal, sobre la cual ejerce su dominio exclusivo, se puede incluso disponer de ella, gravarla, reivindicarla, etc. Sobre la cosa misma, materialmente considerada, cada copropietario no puede obrar sin el consentimiento de los demás. (Zúñiga Torres, 2013, 81)

A pesar de este dominio ejercido idealmente sobre una porción que recae sobre una pluralidad de sujetos, prevalece la naturaleza singular del objeto, por lo que se considera un "llamamiento simultáneo a ejercer el dominio". A cada uno de los copropietarios de un objeto le asiste una serie de derechos, que pueden constituirse por contrato, por tes- 
tamento o por disposición de la Ley. La copropiedad asume dentro de sus caracteres del dominio la exclusividad, y es por esto precisamente que el planteamiento conceptual de copropiedad engloba algunas contradicciones en cuanto a la explicación del hecho jurídico de la copropiedad que ha sido ensayada por diversas teorías. (Castañeda, 1973, 67 - 68)

La comunidad se administra por la voluntad y en la forma que determine la mayoría de los comuneros o copropietarios. La ley concibe a esta modalidad de propiedad como un estado temporal de la propiedad, pues está llamada a no durar más tiempo que los copropietarios quieren que exista (salvo acuerdo cuya duración no puede exceder de cinco años, cualquiera de los condueños puede pedir la partición de la cosa común).

Según Enma Palacios (2005) las características esenciales de la copropiedad son:

a. Contribución en los beneficios y en las cargas: el concurso de los partícipes, y la intensidad del ejercicio de los derechos como de las cargas, es proporcional a sus respectivas cuotas. Mientras no se pruebe lo contrario, las porciones correspondientes a los partícipes en la comunidad se presumen iguales.

b. Uso de las cosas comunes: cada partícipe está facultado para servirse de las cosas comunes, siempre que disponga de ellas conforme a su destino y de manera que no perjudique el interés de la comunidad, ni impida a los copartícipes utilizarlas según su derecho. Sobre esta característica cabe resaltar el problema jurídico de la divisibilidad del uso y goce de la cosa sometida a la modalidad de copropiedad, pues puede ocurrir, con bastante frecuencia, la concurrencia simultánea de la voluntad del uso de la cosa.

c. Contribución a los gastos: los copropietarios tienen derecho para obligar a otros copropietarios a contribuir a los gastos de conservación del objeto común, estando únicamente eximido de esta obligación quien renuncie a la parte que le pertenece en el dominio. Este caso se trata de aquellos gastos necesarios para la conservación de la cosa común, no de aquellos suntuarios o de puro lujo. La renuncia de la cuota implica que se incrementan las cuotas de los demás en proporción a la cuota que tuvieran. 
d. Alteraciones en la cosa común: ninguno de los condueños está facultado, sin consentimiento de los demás, para hacer alteraciones en la cosa común, aunque de ellas pudieran resultar ventajas para todos.

e. Administración y disposición de la cosa común: para la administración y mejor disfrute de la cosa común se vuelven obligatorios los acuerdos de la mayoría de los copropietarios. No existe mayoría sino cuando el acuerdo esté tomado por los partícipes que representen la mayor cantidad de los intereses que constituyan el objeto de la comunidad. Para esto, hay que distinguir los actos de administración (alquilar la vivienda común), que exigen que se adopten por mayoría de intereses (no de propietarios), de los actos de disposición (vender, hipotecar, etc.), en cuyo caso se exige unanimidad. Si no resultare mayoría, o el acuerdo de esta fuere gravemente perjudicial a los interesados en la cosa común, queda a los copropietarios la alternativa judicial, a través de la cual el Juez provee, a petición de parte, lo que corresponda, incluso nombrar un Administrador.

f. Libre disposición de su cuota: todo copropietario tiene la plena propiedad de su parte y la de los frutos y utilidades que le correspondan. Se puede, en consecuencia, enajenarla, cederla o hipotecarla, y aun sustituir otro en su aprovechamiento, salvo si se tratare de derechos personales. Pero el efecto de la enajenación o de la hipoteca con relación a los condueños se encuentra limitada a la porción que le corresponda a cada uno de los copropietarios. (Cuadros Villena, 1995). Evidentemente esto supone que la venta, cesión o hipoteca se refiere exclusivamente a "su cuota", no a la propiedad entera. También hay que tener en cuenta que el resto de copropietarios podrán usar del retracto (derecho a subrogarse con las mismas condiciones estipuladas en el contrato, en lugar del que adquiere una cosa por compra o dación en pago) en el caso de enajenarse a un extraño. (Cuadros Villena, 1995)

g. Acción de división: ningún copropietario está obligado a permanecer en el régimen de copropiedad. Existe por tanto el derecho de cada uno de los comuneros de solicitar la división de la cosa común.

En cuanto a la naturaleza jurídica de la copropiedad, existen tres planteamientos (Palacios, 2005, 75). El primero afirma que cada uno de los copropietarios es titular de una cuota parte indivisa, abstracta e 
ideal. La doctrina suele criticar este postulado en razón que el fundamento de la propiedad es la exclusividad, por la cual el dominio debe recaer sobre una cosa cierta y determinada, lo cual no ocurre en la perspectiva señalada.

Otros señalan que la copropiedad es una cierta clase persona jurídica que nace en forma especial cuando concurren varios propietarios sobre una cosa en común y al efecto estos copropietarios deben limitar sus derechos al cumplimiento de los fines específicos y propios de la copropiedad. Tendencia que también es criticada en razón a que el nacimiento de una persona colectiva está limitada al cumplimiento de requisitos para su formación, en especial un objeto social determinado. Así, esta tesis confundiría el cuasicontrato de comunidad con el de sociedad.

Por último, hay doctrinarios que sostienen que la copropiedad es una modalidad del derecho de propiedad que recae sobre un derecho cuyo objeto es una cosa indivisa donde existen una pluralidad de sujetos, tendencia que es la más aceptada por nuestro ordenamiento jurídico.

Para explicar la copropiedad se han formulado las siguientes teorías: (Palacios, 2005, 75)

a. Teoría de la Interinidad: mientras el bien permanece en estado de indivisión, cada uno de los copropietarios no tiene un verdadero derecho de propiedad, pues está condicionado a la concurrencia de los demás cotitulares. En todo caso habría un derecho debilitado, o un derecho real distinto al de propiedad.

b. Teoría de la Unificación del Derecho de Propiedad: en la comunidad de bienes existe un único derecho de propiedad, aunque atribuido a un grupo de personas en cuanto a la colectividad, o a una persona jurídica constituida por esa colectividad.

c. Teoría de la División: no hay un derecho único, sino tantos derechos como individuos tiene la comunidad.

d. Teoría de la Propiedad Plúrima Total: Cada comunero tiene derecho de propiedad pleno, si bien limitado en cuanto a su ejercicio por la existencia de iguales derechos con los demás, ya que la cuota de participación es la que determina la cantidad de facultades dominicales que se ejercen de forma individual, quedando extraídas del ámbito de poder de cada comunero las facultades de carácter colectivo. 
Todas las teorías que justifican la existencia de la copropiedad reconocen que son principios inherentes a esta modalidad del dominio: (Palacios, 2005, 75)

a) Principio de autonomía privada: los convenios o acuerdos entre los copropietarios rigen preferentemente la organización interna de la comunidad.

b) Principio de proporcionalidad: los copropietarios participan en las ventajas, como en las cargas, del bien común de acuerdo con el porcentaje de su respectiva cuota y en su misma intensidad proporcional.

c) Principio democrático: las decisiones conjuntas sobre el bien común se adoptan de acuerdo con el principio democrático de las mayorías cuando ello es posible. Sin embargo esta democracia se en virtud al porcentaje de cuotas, y no por cabezas.

d) Principio de libertad individual: cada propietario conserva su libertad individual con respecto a su cuota, la cual puede ser transferida, gravada o dispuesta por el comunero sin necesidad de pedirle autorización a otros.

Otro aspecto fundamental a analizar dentro de la naturaleza jurídica es la fuente de constitución de la copropiedad; es decir, como nace concretamente la situación de copropiedad. Según Jorge Castañeda (1973) la copropiedad tiene las siguientes fuentes:

a) Por los contratos: dos o más personas adquieren el dominio de un bien de manera voluntaria sin constituir entre ellas sociedad, pero aceptan ser propietarios en porcentajes determinados.

b) Por la adjudicación en un proceso de partición: ocurre mediante sentencia judicial en un juicio de partición, concretamente en el remate de un bien; en estos casos las personas son coparticipes de los bienes que serán partibles, pero por su condición de bien indivisible únicamente pueden adjudicarse cuotas.

c) Por adjudicación en juicio ejecutivo: lo mismo si la adjudicación se hace a dos o más personas, con ocasión del cobro de una deuda proveniente de un título ejecutivo. 
d) Por sucesión por causa de muerte: para el caso de los herederos universales que de manera pro indiviso suceden al causante en sus activos y pasivos.

e) Por actos de última voluntad: si a través de un legado se lega un bien a dos o más personas conjuntamente, no es el caso de la institución de los herederos, porque con ella se crea un estado de comunidad o pro-indivisión que nace de la herencia. Sin embargo, puede ocurrir que los coherederos solo sean de un bien determinado por lo que entre ellos existirá co-propiedad o comunidad.

\section{f) Por sociedad conyugal}

g) Por la disolución de una sociedad mercantil: en esta situación el activo resultante se repartirá y adjudicará entre los socios en la forma prevista en el estatuto en su defecto en proporción al importe nominal de las acciones.

En cualquier caso, los copropietarios gozan de plena facultad de disposición jurídica de cuota sea a título gratuito u oneroso, y una limitada facultad de disposición material pues deben contar con la autorización de todos los copropietarios. En cuanto a la administración de los bienes comunes, todos los copropietarios tienen derecho a administrar la cosa común en forma igualitaria y así percibir los frutos que esta propiedad produzca. Esta administración se podrá realizar a través de acuerdos fijados en estatutos internos que rijan la copropiedad. (Cuadros Villena, 1995, 56).

\section{DIVISIÓN DE LA COSA O BIEN COMÚN}

La división de un bien común hace referencia al acto jurídico en virtud del cual cesa el estado de indivisión y cada propietario tiene en reemplazo de su cuota virtual que equivale a una parte material del terreno. Ya que el estado de indivisión no puede ser perpetuo porque nadie puede estar obligado a permanecer en la indivisión, la división se conseguirá por el consentimiento de los copropietarios o en su defecto a través de una orden emanada del juez competente, previo trámite correspondiente siempre y cuando la cosa sea divisible, ya que si no lo es se procederá al remate del bien para que el producto obtenido sea dividido entre los copropietarios conforme a las cuotas que les corresponde a cada uno. (Cuadros Villena, 1995) 
Aunque nadie puede estar sujeto a una indivisión permanentemente (temporalidad de la indivisión), es posible que por pacto de los copropietarios se pueda acordar permanecer en la indivisión por un tiempo que no sobrepase los 5 años.

Para la procedencia de la división de la cosa común se deben tomar ciertos aspectos en cuenta, ya que no se podrá dividir una cosa cuando está dividida no podrá cumplir con la utilidad que ofrece sin dividirse y/o también se debe tener presente que la división no procede cuando la superficie no alcanza para su división e inscripción en Derechos reales y en el Registro de la Propiedad.

En función de su factibilidad para la división, la copropiedad puede ser común (o sin indivisión forzosa) y con indivisión forzosa. La copropiedad común o sin indivisión forzosa ocurre en la situación en la que un objeto puede dividirse en cualquier momento a simple solicitud de uno de los copropietarios, división y partición ${ }^{82}$ que podrá hacerse de forma voluntaria o por la vía judicial si fuese necesario. La copropiedad con indivisión forzosa sucede en el caso que la cosa común no puede ser objeto de división, ni siquiera por voluntad de las partes, ya que la normativa aplicable al caso puede llegar a limitar el derecho a dividir la cosa por ser indivisible materialmente o si al ser dividido pierda su esencia y utilidad.

El estado de la indivisión forzosa resulta de la ley y de la voluntad de las partes. Y los casos de propiedad con indivisión forzosa con:

- La copropiedad que resulta de los accesorios indispensables, como ser pasillos, ascensores, etc.

- Los sepulcros

- La propiedad horizontal

- El muro medianero

82 La partición es el derecho de cualquier copropietario, o de un acreedor de este, a que la cuota individual del comunero se concrete en el dominio sobre una porción material del bien común o subsidiariamente en dinero o en otro bien. La partición se puede realizar por acto jurídico o por acto jurídico con homologación judicial, o simplemente a través de un acto judicial cuando no exista consentimiento de las partes. 


\section{LA PROPIEDAD HORIZONTAL Y LA COPROPIEDAD}

La propiedad horizontal es una modalidad de la propiedad orientada al sector urbano en donde se comparte un interés social, la cual está regulada por las leyes especiales del régimen de propiedad horizontal. (González Barrón, 2003, 670). La propia legislación prevé igualdad para la construcción de viviendas, según la necesidad poblacional, el uso de suelo orientado hacia el cumplimiento del interés social, entre otros fines.

En el caso de la propiedad horizontal el dominio se encuentra limitado y afectado por un régimen mixto, ya que se encuentra regulado por la Ley de Propiedad Horizontal, Código Civil y Ley de Inquilinato (únicamente en el caso del dominio privado que se ejerce en la relación arrendador-inquilino). Además, nacen nuevos derechos derivados de la aparición de una nueva entidad jurídica denominada consorcio o copropietarios, que ejerce su derecho sobre su inmueble, el mismo que no es divisible.

Se puede señalar como diferencias entre copropiedad y propiedad horizontal las siguientes (Palacios, 2005, 79):

a) En la copropiedad, el titular del derecho tiene cuotas ideales o cuotas o alícuotas sobre el bien objeto del derecho de propie$\mathrm{dad}$, en tanto que en la propiedad horizontal una persona ostenta propiedad exclusiva sobre una unidad de vivienda independientemente de otras.

b) En la copropiedad, todos los copropietarios tienen el derecho a servirse del bien común, mientras que en la propiedad horizontal rigen criterios espaciales, en la que cada sujeto es titular exclusivo de su unidad de vivienda la cual goza y disfruta con algunas limitaciones alguna y, a la vez, tiene un derecho indivisible junto con los demás propietarios sobre las demás áreas comunes.

c) En la copropiedad, hay pluralidad de sujetos y una unidad de objetos en tanto que en la propiedad horizontal cada titular del departamento excluye a otros.

d) La copropiedad se reglamenta por las normas del Código Civil y se administra por la decisión de la mayoría del porcentaje de las cuotas de los copropietarios. En la propiedad horizontal, existe un 
reglamento interno, que regula los límites al dominio privado que ejercerán los condóminos, así como el régimen de dominio aplicable a las áreas comunes.

e) En la copropiedad, la cuota indivisa del bien se extiende al suelo, al subsuelo, y sobresubsuelo de manera ilimitada donde hasta es útil a los copropietarios; en cambio, en la propiedad horizontal, el dominio exclusivo del departamento se extiende hasta el límite de las secciones superiores e inferiores.

f) Finalmente, el régimen de copropiedad se extingue por la partición voluntaria o forzosa de la misma, mientras que la propiedad horizontal puede extinguirse, por destrucción total o parcial de las tres cuartas partes en el que sea producto de fuerza mayor o de naturaleza, por la compra de los derechos por una sola persona o copropietario, y por el desafecto del inmueble de la propiedad horizontal. (González Barrón, 2003).

Resulta habitual que se asocie la propiedad horizontal con el condominio, sin que sea precisa esta afirmación. El Condominio, es el derecho real de copropiedad de dos o más personas sobre una cosa propia, por una parte indivisa. (Cuadros Villena, 1995, 60). Consiste en la situación en la que la propiedad de una cosa es compartida por dos o más personas. Por extensión, algunos autores denominan así a un inmueble bajo el régimen de propiedad horizontal. (Zúñiga Torres, 2013, 40)

En el condominio es importante regular la forma en que los copropietarios van a tomar las decisiones con respecto a la propiedad que tienen en común. A tal efecto, pueden darse relaciones de mancomunidad o de solidaridad. También es importante regular los casos de extinción de la copropiedad y disolución de la comunidad de bienes (Zúñiga Torres, 2013, 40).

El condominio puede clasificarse de acuerdo con el funcionamiento y aprovechamiento de los elementos comunes, en:

a) Simples: cuando las áreas comunes y sus obras de infraestructura y equipamiento, corresponden a una sola unidad condominal, o;

b) Compuesto: cuando una parte de sus áreas comunes y obras de infraestructura y equipamiento, son aprovechadas por los ti- 
tulares de dos o más unidades condominales, que coexisten en un mismo predio.

En atención a la distribución de las áreas privativas y comunes el condominio puede ser:

a) Horizontal: cuando a cada condómino le corresponde como área privativa una fracción o lote del predio, con su edificación e instalaciones.

b) Vertical: cuando la totalidad del predio es bien común y una misma estructura arquitectónica, se divide en áreas privativas, o;

c) Mixto: cuando concurren las condiciones a que se refieren los párrafos anteriores, para los condominios horizontal y vertical.

\section{LOS PROBLEMAS JURÍDICOS DE LA COPROPIEDAD}

La naturaleza jurídica del régimen de copropiedad la hace susceptible de ocasionar conflictos entre los copropietarios que requieren la intervención judicial. Esto se debe a que usualmente los comuneros (propietarios del bien en común), no acceden a esa situación de copropiedad voluntariamente, sino como consecuencia de la decisión de un tercero (como en el caso de sucesión por causa de muerte), o del cambio de régimen patrimonial (como la disolución y partición de la sociedad conyugal).

En principio, el ordenamiento jurídico parte de la base que el estado ideal de las cosas es que cada bien inmueble tenga un único propietario. La realidad cotidiana va justo en el sentido opuesto, porque lo común es que los bienes inmuebles tengan más de un dueño. El estado de copropiedad o de comunidad de bienes es considerado como un cuasicontrato dentro de la legislación ecuatoriana y viene definido de modo muy claro y preciso en el artículo 2204 del Código Civil Ecuatoriano: "La comunidad de una cosa universal o singular, entre dos o más personas, sin que ninguna de ellas haya contratado sociedad o celebrado otra convención relativa a la misma cosa, es una especie de cuasicontrato".

A pesar de existir regulación suficiente en torno al régimen de copropiedad, en no pocas ocasiones, los conflictos surgen en aspectos referidos como la administración y el uso sobre la cosa común. Frente 
a esta problemática, surge la pregunta: ¿Qué se puede hacer cuando una persona no quiere continuar en la situación de copropiedad de un bien común? La respuesta parece a priori sencilla: el copropietario puede vender su parte al resto de copropietarios o alternativamente adquirir la parte alícuota del resto de propietarios.

Usualmente esta alternativa puede no ser del interés de los copropietarios por muy distintas razones, principalmente por no convenir a sus intereses, en cuya circunstancia la solución que brinda el artículo 2212 del Código Civil establece: "ningún copropietario estará obligado a permanecer en la comunidad. Cada uno de ellos podrá pedir en cualquier tiempo que se divida la cosa común". El citado artículo 2212 contiene lo que se denomina acción de división de la cosa común o actio communi dividundo. ${ }^{83}$ Esta división puede ocurrir de dos modos:

a) Extrajudicialmente: los copropietarios pueden hacer la partición a través de un convenio unánime. En el caso de bienes inmuebles, el convenio deberá ser celebrado por escritura pública y contar con la factibilidad de Gobierno Autónomo Descentralizado Municipal competente.

b) Judicialmente: es la que se lleva a cabo por el juez, previo juicio de partición, o previa adjudicación. La acción puede ser incoada por cualquier copropietario o acreedor de este.

Al amparo de la normativa ecuatoriana existe imprescriptibilidad de la acción de partición, de esta manera ninguno de los copropietarios y ninguno de los sucesores puede adquirir por prescripción los bienes comunes. La acción de prescripción no prescribe ni se extingue en el tiempo y puede solicitarse en cualquier momento y por cualquier

83 Acción de división de condominio o de cosa común. En el Derecho romano clásico, la acción para obtener la división de los bienes comunes, cualquiera fuera el título de la proindivisión, salvo la sucesoria entre coherederos. La fórmula contenía una adjudicativo que autorizaba al juez para adjudicar la propiedad total de la cosa a uno de los condueños; o, a cada uno de los condóminos, una parte de la cosa en propiedad exclusiva. En el Derecho justinianeo, la acción de buena fe y mixta (a la vez personal y real) tendente o la división del condominio y a resolver las demás cuestiones relacionadas con la indivisión. Esta acción es imprescriptible; pero puede estar sujeta a la exclusión temporal por convención o por obligación constitutiva, como la voluntad en contrario del testador, (v. División de la Cosa Común.) 
copropietario, lo que es una consecuencia de la obligatoriedad para poner fin a la indivisión.

Como se expresó con anterioridad el problema fundamental de la copropiedad es la división de la cosa común; lo que se pretende al ejercitar esta acción es dividir físicamente el bien coparticipado. Para que un bien pueda ser dividido las partes resultantes de la división tienen que ser funcionales y conservar sus características esenciales. Por ejemplo: un terreno ubicado en una zona rural de cuatro hectáreas puede dividirse fácilmente en dos parcelas de dos hectáreas cada una o en cuatro si fuere el caso y cada una de las partes resultantes tendrían objetivamente funcionalidad propia y podrían adjudicarse en pleno dominio a cada uno de los copropietarios. En este caso la partición del bien no acarrearía ningún problema debido a que la división es factible jurídicamente, siempre y cuando la normativa que regula el ordenamiento territorial seccional así lo permita.

Debido a que no todos los bienes inmuebles pueden ser físicamente divididos (por ejemplo un departamento, o un bien sometido al régimen de propiedad horizontal), pues las hipotéticas cuotas que pudieran resultar de dividir un bien indivisible no serían funcionales, lo que corresponde es convertir el bien indivisible en un elemento fácilmente divisible. Para el efecto, el ordenamiento jurídico establece que en supuestos de indivisibilidad material del bien, este deberá ser rematado y el dinero así obtenido deberá entregarse a los copropietarios en idéntica proporción a su grado de participación en el bien. El problema resultante de esta operación suele ser el castigo sobre el avalúo real del inmueble, situación que afecta a todos los copropietarios. En el escenario de la subasta de un bien inmueble se permite que cada copropietario pueda participar activamente para intentar adjudicarse el bien en su totalidad, con preferencia a igualdad de oferta sobre cualquier otro pujador, dada su condición de propietario.

En cuanto a los bienes muebles el problema principal se refiere a su uso, goce y administración, que usualmente suele recaer en uno de los comuneros mientras se aclara su destino jurídico. Son escazas las alternativas del resto de copropietarios frente a una situación de hecho que requiere una acción judicial para ser resuelta. 


\section{CONCLUSIONES}

La copropiedad es una modalidad del derecho de propiedad que recae sobre un derecho cuyo objeto es una cosa indivisa donde existe una pluralidad de sujetos. Su naturaleza temporal (o interina) y su forma de administración, basada en la voluntad de la mayoría de los condóminos, la hace un régimen imperfecto no desde el punto de vista jurídico, sino desde el punto de vista fáctico. El conflicto de intereses que ocurre entre los copropietarios hace necesaria la existencia de múltiples alternativas que viabilicen la división de la cosa común, tendiendo siempre hacia la consolidación de la propiedad.

En el ordenamiento jurídico ecuatoriano, la situación de copropiedad se subordina a la autonomía de la voluntad de las partes, de manera que si todos los copropietarios llegan a decidir de manera unánime sobre el bien compartido, el Derecho Civil respalda esa decisión, permitiendo que el bien pueda ser traspasado o gestionado en común, si así se desea. Sin embargo, la solución voluntaria no es viable en el caso de existir posiciones enfrentadas sobre el destino del bien compartido, frente a lo cual únicamente resta la partición judicial del bien común. Ésta resolución dependerá de la naturaleza divisible o indivisible del objeto.

\section{REFERENCIAS BIBLIOGRÁFICAS}

Bernal, B. y Ledesma, J.J. (1981). Historia del Derecho Romano y de los derechos neoromanistas. Tomo I. De los orígenes a la alta edad media. México: Universidad Nacional Autónoma de México. Instituto de Investigaciones Jurídicas.

Cabanellas de Torres, G. (1979). Diccionario jurídico elemental. Argentina: Editorial Heliasta S.R.I.

Calderón Sumarriva, L. (2002). ABC del Derecho Civil. Lima, Perú: Editorial San Marcos.

Carrión Eguiguren, E. (1982). Curso de derecho civil de los bienes. Cuarta Edición. Quito, Ecuador: Ediciones de la Universidad Católica. 
Castañeda, J. E. (1973). Los Derechos Reales. Lima, Perú.

Codificación de la Ley de Propiedad Horizontal.

Código Civil Ecuatoriano

Cornejo Manríquez, A. (2007). Derecho Civil. Santiago, Chile: Editorial Jurídica.

Couture, E. (1960). Vocabulario Jurídico. Montevideo.

Cuadros Villena, C. (1995). Derechos Reales. Lima.

D’Ors, A. (1997). Derecho privado romano (9a. ed.) Pamplona: Universidad de Navarra.

Ghersi, E. (2005), La regulación de mejoras desde el punto de vista económico, Revista Advocatus 11 2014-II, Lima, Perú

Gonzalez Barrón, G. (2003). Curso de Derechos Reales.

Gonzáles Barrón, G. (2010), La construcción en suelo ajeno no es una modalidad de mejora, Diálogo con la jurisprudencia $N^{\circ} 145$, Octubre, Gaceta Jurídica, Lima, Perú.

González, N. (2007), Derecho Civil Patrimonial-Derechos Reales, Palestra Editores, Lima, Perú.

Iglesias, J. (1972). Derecho Romano. Instituciones de Derecho Privado. (6a. Ed.) Barcelona: Ariel

Larrea Holguín, J. (1991). Índice analítico del Código Civil. Tercera Edición. Actualizada. Guayaquil, Ecuador: Corporación de Estudios y Publicaciones.

Mejorada Chauca, M. (2002). Entre la comunidad romana y la comunidad germánica: La sociedad de gananciales a luz de la interpretación jurisprudencial. En: Revista Advocatus: Universidad de Lima. 115-121

Moisset de Espanés, L. (1998). Clases de Derechos reales. Córdoba: Advocatus 
Nicolò, R. (2005). Las situaciones jurídicas subjetivas, Traducción de Carlos Zamudio Espinal y revisada por Rómulo Morales Hervias. En: Advocatus, Revista editada por alumnos de la Facultad de Derecho de la Universidad de Lima, $\mathrm{N}^{\circ}$ 12, Lima. 109.

Palacios, E. (2005). La Copropiedad. Revista Jurídica "Docentia et Investigatio", Facultad de Derecho U.N.M.S.M., Vol. 7 N¹, Lima, Perú

Pañalillo Arévalo, D. (1990). Los bienes, la propiedad y otros derechos reales, Colección Manuales Jurídicos, 2da. Edición, Santiago de Chile. 11-21.

Parraguez, L. (1999). Manual de Derecho Civil Ecuatoriano.

Zúñiga Torres, N.L. (2013). Los juicios de inventario y partición judicial de bienes sustanciados en los juzgados segundo y sexto de lo civil de zamora chinchipe, período 2009-2011, en relación con el estado del trámite, con observancia del debido proceso su incidencia jurídica. Obtenido de $<$ http://dspace.ucacue.edu.ec/bitstream/reducacue/1803/4/ TESIS\%20LENIN\%20ZU\%C3\%91IGA.pdf >>

Recibido: 08/09/2017

Aceptado: $24 / 05 / 2018$

María Gabriela Morillo Chamorro: Investigadora Jurídica PUCE Quito

Mgtr. Gonzalo Lascano Báez: Decente titular PUCE (Facultad de Jurisprudencia)

Correo electrónico: magabrielam@outlook.com

Correo electrónico: gglascano@puce.edu.ec 